\title{
WRITER'S WAYS TO INTERACT WITH \\ READERS IN THE TEXTS WRITTEN \\ BY THE STUDENTS OF ENGLISH \\ EDUCATION DEPARTMENT IN MURIA \\ KUDUS UNIVERSITY
}

\author{
Aisyah Ririn Perwikasih Utari \\ Universitas Muria Kudus \\ aisyah.ririn@umk.ac.id
}

\begin{abstract}
Written text is more complex than spoken text. The interaction between the sender and the receiver are not intensively reached. Readers can only give response without being known by the writer. This is why the writer should write the text in some consideration of leading the readers to read further or even give comments. This research is a qualitative research, which aims to find out the writer's way to interact with readers in four components: 1) clause structure, 2) terms of address, 3) modality, 4) evaluating phenomena. The data of the research is the writer's way of interacting with readers and the source is the texts written by the students of English Education Department in Muria Kudus University. The result of the research covers that most of the writers use statements and questions as the clause structure. The terms of address used are "we", "you", and "I". The modality which is mostly used is medium degree such as "can". The evaluating phenomena are about the sharing of life experience. There are some other ways of writer's interaction with readers through texts that can be conducted in the next research.
\end{abstract}

Keywords: Writer's way, interacting with readers, written texts 


\section{INTRODUCTION}

Texts, based on its form, are divided into two: spoken and written. There are some certain purposes when people produce texts, one of them is having a kind of interaction with others. Communication cannot be separated from language. To make the communication successful, there must be an interaction between or among speakers and hearers, as well as writers and readers. It seems to be odd when the interaction between writer and reader is discussed, mostly because the question that might be raised is "how can a writer interact with his or her reader?" or a statement of "it is impossible for a writer to know his or her reader supposed to be." It can be a little bit uncommon, but the truth is yes, a writer can interact with his or her reader through some texts. Leading questions can also help writers to formulate the text into the interesting one (Williams and Severino, 2004: 166). It means that a text is not always started using a statement as an information for the reader, but it also can be started using some questions to make the readers curios to read further.

There are various kinds of sentences that can be provided in a text. It can be in the form of statement, question, command, offer, and many more. This also can be the choice of interacting with readers for writers. In spoken texts, a speaker can easily get a direct response from the hearer because it is orally sent and the speaker knows whom he or she is talking to. It is quite different from written texts, which happens to a writer who wants to invite the readers to read further or to know more about the writing. This is one of the reasons why a writer should use an interesting title or even introduction when he or she writes a text.

The view of written texts as embodying interaction between the writer and the reader is now well established, and underlies many aspects that may be focused on in attracting the readers to read the texts further (Thompson, 2001:58). The main purpose of writing a text is to invite the readers to find an information, opinion or idea provided by the writer. The writer should lead the readers to be interested in the text. There are four ways in interacting with readers in general; 1) clause structure, 2) terms of address, 3) modality, and 
4) evaluating phenomena. Those are four ways from, perhaps there are many more ways can be done by writers to interact with readers through writing works. These ways of interactions are also usually used by online bloggers who likes to write and publish their works in the internet. They always have their unique ways to invite and make the online readers visit and read their blog.

The first way of interacting with readers is clause structure. There are various kinds of clause structure that can be chosen by a writer to interact with readers, for example; questions, exclamations, statements, yes/no questions, offers, or even command. As well as spoken texts, written texts also have its function for a writer to expect readers' response to his or her works, no matter how the readers are interested or not. The efforts of making the interaction become compulsory to fulfill the requirement of good writing.

Terms of address are also useful to show the close relation between the writer and the readers. It seems to be a real relationship that can cut the gap of them and it is not impossible that the readers would feel comfortable in reading the texts. It usually happens to a best seller book writer. He or she is always searched by his or her fans to meet or even wait for the next interesting works. The third way is modality. In English, there are some different degrees of modality, based on both the writer's and readers' perspectives, such as; low degree modality, medium degree modality, and high degree modality. On the other words, the degree is what the writer suggests or enforces the readers to do and follow something. For example, "should" is a medium degree modality and "must" is high degree modality. The last way of interacting with readers is evaluating phenomena. This can be done by a writer to make a judgment and appreciation to the readers through some information provided in the text. It also shows the writer's way to lead the readers' opinion of something happen in certain ways.

The students of English Education Department in Muria Kudus university started to practice their English writing skill in the Paragraph Writing Class. There are some duties of writing texts which consist of various chosen topics. Naturally they are taught how to make an interaction with their readers when they write Eng- 
lish texts. Some of the works are analyzed in this research. It is quite interesting because they are intermediate learners and there must be various ways of choosing how to interact with the readers supposed to be.

The statement of the problem is "how the writer's ways of interacting with readers in the texts written by the students of English Education Department in Muria kudus University?”. Based on the statement of the problem which is previously mentioned, the objective of the research is 'to find out the writer's ways of interacting with readers in the texts written by the students of English Education Department in Muria Kudus University."

The research is limited to the analysis of the writer's ways to interact with readers in the texts written by the students of English Education Department in Muria Kudus Universtity. The texts are from the final project of texts written in the Paragraph Writing class of the students in second semester.

\section{BACKGROUND LITERATURE}

\subsection{Written Text}

As what it is called, a written text is a text which is produced in the form of printed or online. In the written text, the ones who are involved are the writer and the reader. As well as spoken text, which involves speaker and hearer, there is also an interaction between the writer and the reader in written text. A successful written text should fulfill the requirement of having the readers interested to read further about the text. This is why the writer should be creative in making the title until the introduction of the text. While reading, the reader is relating what has been stored to incoming information and readjusting interpretations as required (Papalia, 2016:70). A direct point of the introduction will always be liked by the readers because too many useless chit chat will make the text boring. Even though the purpose of a certain text is to give information, the writer can start the introduction by giving a question or a riddle so that the readers can be interested and curious to find the other information which is meant by the writer. Information is not always provided by a statement, but it also can be provided by giving a 
question, or even a command.

Written texts are a little bit complex then spoken texts. In spoken texts, the speaker should not have to wait for a long time to get a response from the hearer. It is different with written texts. A writer, for sure, does not know who his or her readers are supposed to be. It is like a passive waiting process of getting a feedback or response. It needs time to know whether the readers are interested with his or her writing or not. A book writer will wait to make sure whether his or her book is sold well or not. And a blogger will wait whether their web blog is visited and read by many online visitors or not. All of them depend on the quality of the text itself. This is why a written text is considered as a complex text, especially in getting a direct response from the readers. There is nothing to do by the writer, instead of making an effort to make an interaction with his or her readers to attract them in reading the work.

\subsection{Ways to Interact with Readers in Written Texts}

Generally, there are four ways of how to interact with readers for the writer of a text. If all the main requirements are fulfilled, the writer can be successful in making the readers interested in reading his or her text further. Arguments, results, and interpretations need to be presented in ways that readers are likely to find both credible and persuasive, and this means writers must draw on familiar ways of expressing their arguments, representing themselves, and engaging their audiences (Hyland, 2001: 549). Because the function of how to interact with readers for writer is not only to have a communication with them, but also to succeed leading them to know more about the information provided in the text. The four ways of interacting with readers can be discussed below.

\section{Clause structure}

Clause structure can be formed in some ways, such as: question, exclamation, statement, yes/no question, or a command. Giving information is not always done by giving a statement that cannot be responded directly by the readers. Here, the readers will feel that they are involved in the experience of the writer's story written in the text. For example, "have you ever wondered 
about the sea?" the question is raised in the introduction to encourage the readers to think about something. It is possible that the readers can make a direct response to answer the question.

\section{Terms of Address}

Addressing someone in spoken texts is quite common. In written texts, to make the interaction between the writer and the reader closer, terms of address can be used, too. For example, a writer can use "you" to address the reader when he or she wants to suggest something. When a text is addressed to someone who is known by the writer, it can be a normal term of address, such as: Sir/Madam.

\section{Modality}

Modality is the way speakers or writers interact with their listeners or readers by taking up positions or point of view in statements, questions and commands. There are some different degrees of modality based on the point of view: low, medium, and high. They do that by expressing different degrees of probability, usuality, obligation and inclination (tendency). The examples are as follow:

a. Probability: "There are three possible reasons why students like to learn English."

b. Usuality: "How often do you write?"

c. Obligation: "You must not be absent at school."

d. Inclination: "Would you like a glass of milk?"

\section{Evaluating Phenomena}

Writers and speakers use particular types of vocabulary in order to make positive and negative evaluations of range of phenomena. The range of phenomena includes the feelings of the characters in the text, the moral judgements of people's behavior in the text and the quality of objects such as artistic works, people's appearance or other natural or man-made phenomena. This evaluative vocabulary is called attitude.

\section{METHODS}

\subsection{Design of the Research}

Qualitative research design is suitable for this research. The 
data will be taken and analyzed in qualitative ways. Bogdan and Biklen (1992:30) state that one of the characteristics of qualitative research is descriptive. The result is also discussed descriptively by describing the analyzed data based on the objective of the research.

\subsection{Data and Data Source}

The data of the research is the writer's ways to interact with the readers in the texts. There are four ways of interacting with readers: clause structure, terms of address, modality, ad evaluating phenomena. The data source is the texts written by the students of English Education Department in Muria Kudus University.

\subsection{Data Collection and Analysis}

The data is collected from the final assignment written in the paragraph writing class which is written by the students of English Education Department in Muria Kudus University. The texts will be taken $10 \%$ randomly from 30 texts. So there are 3 texts need to be analyzed intensively. The analysis will be limited on the writer's four ways of interacting with readers, based on the theory given in chapter 2 .

\section{FINDINGS}

The finding and discussion are discussed in one session because the data and the result are provided in the same way: descriptive analysis. The result of the 3 data will be discussed one by one.

In the first text, the analysis is divided into four components which fulfill the requirements of interacting with readers by the writer. The clause structures used by the writer are statements, questions, exclamations, and yes/no questions. The various clause structures show that the writer really realizes the interaction with her readers. Next is the term of address used by the writer are "we" as the symbol of close relationship that the writer tries to make with the readers; "I" is to emphasize that the writer describes her own experience and opinion as the information for the readers. The next term of address used is "you" to address the readers directly. 
It shows that the writer wants to suggest something or point out something related to the readers' response. The degrees of modality used by the writer in the text are "can", "may", and "could". Most of the modality used are medium degree because the writer wants to suggest something to the readers in polite and comfortable ways. There is one low modality used: it is "may". It can be a kind of possibility in which the writer is not sure about the information given in general. The evaluating phenomenon is about people's relationship and it deals with people's attitude, in this way as the readers, about facing the past and future by comparing her own experience.

In the second text, the clause structures mostly chosen by the writer are statements and questions. The writer tries to attract the readers' interest by introducing something in the form of information and also leading the readers' response by giving some questions. The terms of address used are "we", "they", and "you". The address of "we", in general, invites the readers to make a feeling of close to the writer. The pronoun "we" shows that the things informed can happen to both the writer and the readers. The term "they" is described as the comparison between the writer and the reader: as we know that "they" is the third person point of view. The last term of address used is "you". It shows a direct way to point out that the target is the reader. The writer tries to make an interaction or suggest something for the reader. The degrees of modality used in the text are "have to" and "can". Both of them are medium degrees of modality. They are used when the writer wants to suggest something for the readers but not enforce them to do so. The evaluating phenomenon found is the attitude of predicting the future, which is generally done by many people. The writer compares the things done by her, readers, and other people in this world.

The clause structure of the third text mostly consists of statements and questions. The statements tell about the writer's experience about life. The information given can make the readers compares the writer's point of view and their own point of view. The terms of address mostly used are "I" and "you". The simple "I" can make the readers relaxed in reading the text because it feels like the writer getting so close with the reader. That is why the writer choos- 
es to address herself as "I". "You" is mostly used as the feedback of "I". If there is "I", there should be "you". It is a complete thing of relationship between the writer and the reader. The degree of modality used is only "can" in which it is a medium degree of modality. The politeness of not enforcing the readers to do something is still applied in the text. The evaluating phenomenon is about life experience in which the writer does not judge anyone's experience but she tries to share her real experience to be compared by the readers whether there is a moral value that can be taken or not.

\section{CONCLUSION}

Writer's interaction with his or her readers is very important to apply in a written text. Beside of the purpose of providing clear information, but it also can lead the readers to be interested in reading the text further. The clause structures which are mostly used are statements, questions, exclamations, and commands. The terms of address found are "you", "we", and "I" to make a close relationship between the writer and the reader. The degrees of modality which are mostly used are "can", "have to", and "might". They are medium degree of modality that shows a comfort suggestion from the writer to the readers. It is suggested for the next researcher to conduct the same research topic with different components of how to interact with readers for writer. 


\section{REFERENCES}

Hyland, Ken. 2001. Bringing in the Reader: Adressee Features in Academic Articles. Sage Publication: Journal of Written Communication

Thompson, Geoff. 2001. Interaction in Academic Writing: Learning to Argue with the Reader. UK: Oxford University Press.

Papalia, Anthony. Interaction of Reader and Text. www.udel.edu.eli.rivers.rivers6. Retrieved on June 29, 2016.

Williams, Jessica and Carol Severino. 2004. The Writing Center and Second Language Writer. Elsevier: Journal of Second Language Writing. 